|| ISSN(online): 2589-8698 || ISSN(print): 2589-868X || International Journal of Medical and Biomedical Studies

Available Online at www.ijmbs.info

PubMed (National Library of Medicine ID: 101738825)

Index Copernicus Value 2018: 75.71

Original Research Article

Volume 3, Issue 9; September: 2019; Page No. 71-76

\title{
STUDY OF CASES OF ARM IN RURAL POPULATION
}

Dr. Mayur Maheshwari ${ }^{1}$, Dr. Jitendra Gothwal ${ }^{2}$, Dr. Manish Patel ${ }^{3}$, Dr. Ravi Gupta ${ }^{4}$

${ }^{1}$ Associate Professor, Index Medical College Hospital and Research Centre, Indore

${ }^{2}$ Assistant Professor, Index Medical College Hospital and Research Centre, Indore

${ }^{3}$ Professor, Index Medical College Hospital and Research Centre Indore

${ }^{4}$ Resident, Index Medical College Hospital and Research Centre Indore

Article Info: Received 27 August 2019; Accepted 14 September. 2019

DOI: https://doi.org/10.32553/ijmbs.v3i9.530

Address for Correspondence: Dr Jitendra Gothwal, Assistant Professor, Index Medical College Hospital and Research Centre, Indore

Conflict of interest: No conflict of interest.

\section{INTRODUCTION}

Anorectal malformations (ARMs) comprise a spectrum of birth defects in newborn male and female children which include rectum, anal canal, genitalia and urinary tract. ARMs incidence ranging 1:2000-5000 live birth. ${ }^{1,2}$ It is very common encountered in pediatric age and continue to present a challenge for pediatric \& neonatal surgeon regarding appropriate diagnosis and outcome.

The embryological basis includes failure of descent of urorectal septum. $^{[3]}$

The spectrum of ARM varies from mild anterior displacement of anus to complex anomalies such as cloacal exstrophy. ${ }^{[4]}$ The main goal of management is correct diagnosis and surgery so as to achieve good anatomic and functional outcome so that a child can lead his or her life as normal as possible.

The social awareness for this anomaly is extremely poor and requires education through poster presentation and educating primary health care workers. What is required is early diagnosis and referral to specialty centres. In this study we have tried to assess the incidence of ARM, discuss the types of surgeries and evaluate their outcome.

\section{MATERIAL AND METHODS}

All children of pediatric age group from 0 to 15 years admitted in surgical wards and/or pediatric wad of Index Medical College, Hospital and Research Centre, Indore with diagnosis of Anorectal Malformations who will undergo all stage of treatment and follow- up. This was prospective and observational study for 18 months with ethics committee approval.

We had included all the children presenting to us during the study period with Anorectal Malformation, whose parents were willing to give consent for participation of their child in the study. Accordingly during the study tenure

we got 32 such children fulfilling all the inclusion and none of the exclusion criteria.

\section{METHODOLOGY}

Initially the prospective children were identified as per the inclusion/exclusion criteria from the wards of our institution. Then the parents of these children were informed about the study, its procedures, risks / benefits in detail, and after getting their verbal approval for participation, a voluntary written informed consent was obtained from the parents and/ or his/her legally acceptable representative. Then all the necessary Investigations and Clinical examination were done and Treatment was planned. Progress and findings recorded as per observation and follow up investigations. The parents and/or his/her relative was given the awareness questionnaire regarding anorectal malformations, to be filled, in case of need, the investigator explained the questions to them and got the response, which were captured by the investigator. Outcome is assessed on basis of Kelly's Score. We have not included preliminary colostomy in our study. We have focused on various definitive Surgeries and their outcome. 
Operative procedures for Different types of Anorectal Malformations were:

a. For Low anomalies: Anoplasty, Primary minimal PSARP.

b. For Intermediate anomalies: Anoplasty, PSARP and Transposition

c. For High anomalies: 3 stage repair with colostomy, PSARP and colostomy closure, PSARVUP

OBSERVATIONS AND RESULTS

Table 1: Distribution of patient according to gender

\begin{tabular}{|l|l|l|}
\hline Gender & No. & $\%$ \\
\hline Female & 13 & 40.6 \\
\hline Male & 19 & 59.4 \\
\hline Total & 32 & 100.0 \\
\hline
\end{tabular}

The above table shows the distribution of patients according to gender.

There were 13 (40.6\%) females and 19 (59.4\%) males in our study, showing a male preponderance.

Table 2: Distribution of patient according to delivery

\begin{tabular}{|l|l|l|}
\hline Delivery & No. & $\%$ \\
\hline Home & 19 & 59.4 \\
\hline Hospital & 13 & 40.6 \\
\hline Total & 32 & 100 \\
\hline
\end{tabular}

The above table shows the distribution of patients according to delivery.

There were 19 (59.4\%) patients who were home delivered, while the rest $13(40.6 \%)$ patients were hospital delivered. Majority of the patients were home delivered.

Table 3: Association between education of parents and awareness of parents

\begin{tabular}{|l|l|l|l|l|l|l|}
\hline \multirow{2}{*}{ EDUCATION } & \multicolumn{2}{|l|}{ Aware } & \multicolumn{2}{l|}{ Not aware } & \multicolumn{2}{l|}{ Total } \\
\cline { 2 - 7 } & No. & $\%$ & No. & $\%$ & No. & $\%$ \\
\hline Educated & 8 & 66.7 & 4 & 33.3 & 12 & 100 \\
\hline Uneducated & 2 & 10 & 28 & 90 & 20 & 100 \\
\hline Total & 10 & 31.3 & 22 & 68.8 & 32 & 100 \\
\hline
\end{tabular}

Pearson chi-square $=11.210, \mathrm{df}=1, \mathrm{p}=0.001$, significant

There was statistically significant association seen between education of parents and awareness of parents $(p<0.05)$, showing that the awareness of parents is dependent on education of parents.

Table 4: Association between type of defect and outcome of surgery

\begin{tabular}{|l|l|l|l|l|l|l|l|l|}
\hline & \multicolumn{2}{|l|}{ GOOD } & \multicolumn{2}{l|}{ FAIR } & \multicolumn{2}{l|}{ POOR } & \multicolumn{2}{l|}{ TOTAL } \\
\cline { 2 - 9 } & No. & $\%$ & No. & $\%$ & No. & $\%$ & NO. & $\%$ \\
\hline LOW & 14 & 100 & 0 & 0.0 & 0 & 0.0 & 14 & 100 \\
\hline $\begin{array}{l}\text { INTER } \\
\text { MEDIATE }\end{array}$ & 10 & 83.3 & 2 & 16.7 & 0 & 0.0 & 12 & 100 \\
\hline HIGH & 1 & 16.7 & 3 & 50.0 & 2 & 33.3 & 6 & 100 \\
\hline Total & 25 & 78.1 & 5 & 15.60 & 2 & 6.3 & 32 & 100 \\
\hline
\end{tabular}

Pearson Chi-square $=19.200, \mathrm{df}=4, \mathrm{P}=0.001$ Significant There was statistically significant association seen between type of defect and outcome of surgery $(p<0.05)$, showing that the outcome of surgery is dependent on type of defect.

Table 5: Association between management and outcome of surgery

\begin{tabular}{|l|l|l|l|l|l|l|l|l|}
\hline \multirow{2}{*}{} & \multicolumn{2}{l}{ GOOD } & \multicolumn{2}{l|}{ FAIR } & \multicolumn{2}{l|}{ POOR } & \multicolumn{2}{l|}{ TOTAL } \\
\cline { 2 - 9 } & No. & $\%$ & No. & $\%$ & No. & $\%$ & NO. & $\%$ \\
\hline Anal & 1 & 50 & 1 & 50 & 0 & 0.0 & 2 & 100 \\
transposition & & & & & & & & \\
\hline ASARP & 4 & 100 & 0 & 0 & 0 & 0.0 & 4 & 100 \\
\hline CUTBACK & 10 & 100 & 0 & 0 & 0 & 0 & 10 & 100 \\
\hline PSARP & 10 & 66.7 & 3 & 20 & 2 & 13.3 & 15 & 100 \\
\hline PSARVUP & 0 & 0 & 1 & 100 & 0 & 0 & 1 & 100 \\
\hline Total & 25 & 78.1 & 5 & 15.60 & 2 & 6.3 & 32 & 100 \\
\hline
\end{tabular}

Pearson Chi-square $=12.800, \mathrm{DF}=8, \mathrm{p}=0.119$, Nonsignificant

There was no statistically significant association seen between management and outcome of surgery ( $p>0.05)$. 
Dr Jitendra Gothwal et al, International Journal of Medical and Biomedical Studies (IJMBS)

Table 6: Association between diagnosis and management

\begin{tabular}{|l|l|l|l|l|l|l|}
\hline Diagnosis & ANAL TRANSPOSITION & ASARP & CUTBACK ANOPLASTY & PSARP & PSARVUP & TOTAL \\
\hline Anal stenosis & 0 & 0 & 4 & 0 & 0 & 4 \\
& $0.0 \%$ & $0.0 \%$ & $100.0 \%$ & $0.0 \%$ & $0.0 \%$ & $100.0 \%$ \\
\hline Anocutaneous fistula & 0 & 0 & 3 & 0 & 0 & 3 \\
& $100 \%$ & $0.0 \%$ & $0.0 \%$ & $0.0 \%$ & $0.0 \%$ & $100.0 \%$ \\
\hline Anovestibular fistula & 0 & 4 & 0 & 0 & 0 & 4 \\
& $0.0 \%$ & $100.0 \%$ & $0.0 \%$ & $0.0 \%$ & $0.0 \%$ & $100.0 \%$ \\
\hline Cloaca & 0 & 0 & 0 & 0 & 1 & 1 \\
& $0.0 \%$ & $0.0 \%$ & $0.0 \%$ & $0.0 \%$ & $100 \%$ & $100.0 \%$ \\
\hline Covered anus & 0 & 0 & 3 & 0 & 0 & 3 \\
& $0.0 \%$ & $0.0 \%$ & $100.0 \%$ & $0.0 \%$ & $0.0 \%$ & $100.0 \%$ \\
\hline Rectobulbar fistula & 0 & 0 & 0 & 4 & 0 & 4 \\
& $0.0 \%$ & $0.0 \%$ & $0.0 \%$ & $100 \%$ & $0.0 \%$ & $100.0 \%$ \\
\hline Rectoprostatic fistula & 0 & 0 & 0 & 3 & 0 & 3 \\
& $0.0 \%$ & $0.0 \%$ & $0.0 \%$ & $100 \%$ & $0.0 \%$ & $100.0 \%$ \\
\hline Rectovesicular fistula & 0 & 0 & 0 & 2 & 0 & 2 \\
& $0.0 \%$ & $0.0 \%$ & $0.0 \%$ & $100 \%$ & $0.0 \%$ & $100.0 \%$ \\
\hline Rectovestibular flstula & 2 & 0 & 0 & 6 & 0 & 8 \\
& $25.0 \%$ & $0.0 \%$ & $0.0 \%$ & $75.0 \%$ & $0.0 \%$ & $100.0 \%$ \\
& & & & & & \\
\hline Total & 2 & 4 & 10 & $46.9 \%$ & $3.1 \%$ & $100.0 \%$ \\
\hline
\end{tabular}

Pearson Chi-square $=100.80, \mathrm{DF}=32, \mathrm{p}=0.000$ Significant

There was a statistically significant association seen between the diagnosis and their management $(p<0.05)$. As the surgeries performed are definitive for the diagnosis, there is a statistically significant association seen between the diagnosis and the management.

Table 7: Association between place of living and education

\begin{tabular}{|l|l|l|l|l|l|l|}
\hline \multirow{2}{*}{ PLACE OF LIVING } & \multicolumn{2}{l|}{ EDUCATED } & \multicolumn{2}{l|}{ UNEDUCATED } & \multicolumn{2}{l|}{ Total } \\
\cline { 2 - 7 } & No. & $\%$ & No. & $\%$ & No. & $\%$ \\
\hline RURAL & 5 & 20.0 & 20 & 80.0 & 25 & 100 \\
\hline URBAN & 7 & 100.0 & 0 & 0 & 7 & 100 \\
\hline Total & 12 & 37.5 & 20 & 62.5 & 32 & 100 \\
\hline
\end{tabular}

Pearson Chl-Square $=14$ 933, DF $=1, p=0.000$ Significant

There was a statistically significant association seen between place of living and the educational status $(p<0.05)$, showing that educational status is dependent on the place of living.

The percentage of educated parents was much higher in urban areas $(100 \%)$ as compared to rural areas $(20 \%)$.

Table 8: Association between delivery and place of living

\begin{tabular}{|l|l|l|l|l|l|l|}
\hline \multirow{2}{*}{ Place of living } & \multicolumn{3}{l|}{ Home } & \multicolumn{2}{l|}{ Hospital } & Total \\
\cline { 2 - 7 } & No. & $\%$ & No. & $\%$ & No. & $\%$ \\
\hline Rural & 19 & 100 & 0 & 0.0 & 19 & 100 \\
\hline Urban & 6 & 46.2 & 7 & 53.8 & 13 & 100 \\
\hline Total & 25 & 78.1 & 7 & 21.9 & 32 & 100 \\
\hline
\end{tabular}

Pearson Chl-Square $=13.095, \mathrm{DF}=1, \mathrm{p}=0.000$ Significant 
There was a statistically significant association seen between place of living and delivery $(p<0.05)$, showing that the delivery is dependent on the place of living. The percentage of hospital delivered children was higher in urbm areas (100\%) as compared to rural areas (80\%).

\section{DISCUSSION}

The management of infants with ARM continues to be a challenge to pediatric surgeons, worldwide. For better results, precise anatomical reconstruction and careful preservation of Structure is required. ARM being a complex group of disorders, is not easy to diagnose at primary healthcare level. The social awareness about the disease is low and it also varies with Sex of child, place of living and education of parents. Our study comprised of prospective and observational study (18 months).

All the defects were classified according to Wingspread classification. Since most publications on the outcomes of ARM predate Krickenbeck, the Wingspread Classification has been used for the rest of the introductory section of this thesis. During the period of study there were only 32 cases of ARM which is $(0.4 \%)$ of admissions.

Out of 32 cases of ARM, 19 were male $\{59.4 \%\}$ and 13 were female $\{40.6 \%\}$. This sex distribution is in accordance with studies conducted by Bhargava et al $(2006)^{[2]}$ in which male patients were $51 \%$ and female patients were $49 \%$ showing slight male preponderance. The Male:Female patient ratio in our study is 1.4:1 which is in accordance with the Male: female patient ratio in studies conducted by Gardikis et al $(2004)^{[11]}$ in which the Male:Female ratio was 1.3:1. In another study conducted by Umesh et al $(2015)^{[3]}$ the Male : Female ratio was 1.17:1 showing Male Preponderance.

The most common Definitive Diagnosis among female patients in our study was Recto Vestibular Fistula (61.5\%) and among Male patients was Recto Bulbar Fistula (21.1\%) and Anal Stenosis (21.1\%). This correlates with the study conducted by Elsayed et al $(2016)^{[12]}$ in which the most common anomaly in females is Rectovestibular fistula (45\%) and the most frequent variant seen in males is rectourethral (bulbar and prostatic) fistula (10\%). Similar results were seen in study conducted by Wakhlu et al $(1996)^{[5]}$ in which Vestibular fistula (43.3\%) was the most common anorectal malformations in female children.
Distribution of Patients according to type of defect in our study was as follows High anorectal malformation accounted for 06 (18.8\%) cases, the intermediate 12 $(37.5 \%)$ and the low types were 14 (43.8\%).

This slightly differed from the Distribution of Patients according to type of Defect in a study conducted by Osagie et al $(2016)^{[9]}$ in which High anorectal malformation accounted for 33 (34.4\%) cases, the intermediate 15 (15.6\%) and the low types were 48 (50\%) and in a study conducted by Statovci et al $(2015)^{[8}$ in which High type anomalies were present in $39.47 \%$, intermediate $17.11 \%$ and low type in $43.42 \%$.

In our study $7.7 \%$ of the female babies had high, $61.5 \%$ intermediate and $30.8 \%$ had low anomalies, whereas $26.3 \%$ males had high, $21.1 \%$ intermediate and $52.6 \%$ showed low malformations. In a study conducted by Bhargava et al (2006), ${ }^{[2]} 20 \%$ of the female babies had high, $76 \%$ intermediate and $4 \%$ had low anomalies, whereas $80.39 \%$ males had high, $3.92 \%$ intermediate and $15.6 \%$ showed low malformations.

Thus the High defects were more common in males whereas Intermediate defects were more common in Females. This is in accordance with study Conducted by Bhargava et al (2006).[2]

The distribution of defects among males and female in our study and study

Conducted by Bhargava et al (2006) ${ }^{[2]}$ was as follows:

Table 9:

\begin{tabular}{|l|l|l|}
\hline Males & Our Study & $\begin{array}{l}\text { Bhargava et al } \\
(2006)^{[2]}\end{array}$ \\
\hline Rectobulbar Fistula & $21.1 \%$ & $3.9 \%$ \\
\hline Anocutaneous Fistula & $15.8 \%$ & $15.7 \%$ \\
\hline Rectovesical Fistula & $10.5 \%$ & $5.9 \%$ \\
\hline Rectoprostatic Fistula & $15.8 \%$ & $11.8 \%$ \\
\hline
\end{tabular}

Table 10:

\begin{tabular}{|l|l|l|}
\hline Females & Our Study & $\begin{array}{l}\text { Bhargava et al } \\
(2006)^{[2]}\end{array}$ \\
\hline Recto Vestibular Fistula & $61.5 \%$ & $61.2 \%$ \\
\hline Ano Vestibular Fistula & $30.8 \%$ & $4 \%$ \\
\hline Cloaca & $7.7 \%$ & $10 \%$ \\
\hline
\end{tabular}

Among the Management procedures Majority of patients underwent PSARP (46.9\%) followed by Cutback Anoplasty (31.3\%) due to the fact that the surgery of choice for Intermediate and High malformations is PSARP. This approach allowed 
surgeons to view the anatomy of these defects clearly, to repair them under direct vision.

The overall outcome of the various surgeries performed based on Kelly's clinical scoring system was Good in $78.1 \%$ cases, Fair in $15.6 \%$ cases and Poor in $6.3 \%$ cases. This closely resembled the Kelly's clinical scoring system based outcome of different surgeries in a study conducted by Umesh et al $(2015)^{[3]}$ in which the outcome was Good in $90 \%$ cases, Fair in $8 \%$ cases and Poor in $2 \%$ cases.

The outcome was better in surgeries performed on male patients with Good results in $78.9 \%$ cases which is in accordance with the study conducted by Umesh et al $(2015)^{[3]}$ in which outcome was better in Males patients with Good results in $92.59 \%$ cases.

Among different Types of Defect in our study, the Outcome in Low anomalies was Good in $100 \%$ of cases which was in accordance with the study conducted by Umesh et al $(2015)^{[3]}$ in which outcome in Low anomalies was Good in $94.73 \%$ cases.

Among intermediate anomalies the outcome was Good in $83.3 \%$ cases, Fair in $16.7 \%$ cases and Poor in $0 \%$ cases. In High anomalies the outcome was Good in $16.7 \%$ cases, Fair in $50 \%$ cases and Poor in $33.3 \%$ cases. This was different from the outcome seen in intermediate and high anomalies in study conducted by Umesh et a1 (2015) $)^{[3]}$ in which among intermediate anomalies the outcome was Good in $50 \%$ cases, Fair in $50 \%$ cases and Poor in $0 \%$ cases and among High anomalies the outcome was Good in $80 \%$ cases, Fair in $10 \%$ cases and Poor in $10 \%$ cases.

Among the major Surgeries performed, the Outcome of PSARP in terms of Kelly's clinical scoring system was Good in $66.7 \%$, Fair in $20 \%$ and Poor in $13.3 \%$.

Scores of the PSARP group in the study conducted by Tsuji et al $(2002)^{[6]}$ in terms Kelly's clinical scoring system was Good in 48\%, Fair in 48\%, and Poor in $4 \%$.

The Outcome of ASARP in terms of Kelly's clinical scoring system was Good in $100 \%$ of the cases. Similar results with ASARP were seen in the study conducted by Sham et al $(2012)^{[7]}$ in terms of Kelly's clinical scoring system. The result was Good in $100 \%$ cases.

The Overall Awareness about the disease among Parents in our study was low (31.3\%). The awareness was less in Parents of female patients (23.1\%) compared to male patients $(36.8 \%)$, the awareness was less in Parents of Patients with Home delivery
(10.5\%) as compared to Hospital delivery (61.5\%) and those who belonged to Rural area (20\%) as compared to those who belonged to Urban area (71.4\%).It was noted probably because of poverty, lack of access to advanced healthcare in rural areas, or neglect of the female children in our society. Similar factors are described in study conducted by Sham et al (2012) ${ }^{[7]}$ who analyze the cause of lack of Social awareness by analyzing the causes of delayed presentation of ARM, which include wrong advice regarding the treatment, inadequate management of ARM elsewhere, delayed diagnosis, lack of money, and lack of social support, inadequate knowledge about the management of ARM, neglect of the female children in our society and lack of access to advanced healthcare in rural areas of Maharashtra (India).

In our study majority of the parents of these patients were from the rural areas (78.1\%). This was in accordance with a study conducted by Mfinanga et al $\left(2018^{[10]}\right.$ where $86.2 \%$ of parents of these patients were from Rural areas.

\section{CONCLUSION}

Males are more commonly affected by these conditions. High and Low variety was more common among males and Intermediate variety was more common among females. Recto Vestibular fistula was by far the most common variant seen. PSARP was the surgery of choice in Intermediate and High varieties. Outcome was good in majority of cases. Awareness about ARM was low among majority of parents. Anorectal malformation is a surgically treatable entity. Early restorative surgery leads to good outcome. Time being the essence, awareness about the condition, hospital delivery and detailed neonatal examination is advisable. In developing countries like India, where illiteracy and poverty are prevalent and where there is neglect of female child, early diagnosis and referral to specialty centres for surgery is always commendable in terms of social acceptance and a sound psyche.

\section{REFERENCE}

1. Gangopadhyay AN, Pandey V. Anorectal malformations. J Indian Assoc Pediatr Surg. 2015 JanMar;20(I):IO-15.

2. Bhargava $\mathrm{P}$, Mahajan $1 \mathrm{~K}$, Kumar A. Anorectal malformations in children. J Indian Assoc Pediatr Surg. 2006;11(3):136-9.

3. Umesh N, Sowmya M. Clinical study of anorectal malformations. Journal of Evolution of Medical and Dental Sciences 2015;4(9):146673. 
Dr Jitendra Gothwal et al, International Journal of Medical and Biomedical Studies (IJMBS)

4. Rintala RJ, pakarinen MP. Imperforate anus :long short term outcome . semin pediatr surg 2008; 17:7989

5. Wakhlu AK. Management of congenital anorech malformations. Indian Pediatr. 1995 Nov;32(II):123942.

6. Tsuji H, Okada A, Nakai H, Azuma T, Yagi M, Kubota A. Follow-up studies of anorectal malformations after posterior sagittal anorectoplasty. J Pediatr Surg. 2002 Nov;37(1 1): 1529-33.

7. Sham $M$, Singh $D$, Phadke D. Anorectal malformations: Definitive management during and beyond adolescence. J Indian Assoc Pediatr Surg. 2012 Jul-Sep; 17(3):]20-3.

8. Statovci $S$, Heta H, Hyseni N, Grajcevci S, Berisha M, Ceku G. Treatment of children with anorectal malformations IO-Year review. Open Access Library Journal 2015;21e1 393.
9. Osagie TO, Aisien E, Osifo OD. Outcomes of Posterior Sagittal Anorectoplasty for High Anorectal Malformation in Benin City, Nigeria J West Afr Coll Surg. 2016 Jan-Mar;6(1):16-30.

10. Mfmanga RJ, Massenga A, Mashuda F, Gilyoma JM, Chalys PL. Patterns and outcome of surgical management of anorectal malformations at a tertiary care hospital in resource limited setting: a Tanzanian experience. Tanzania Journal 2018;20. Online. of Health Research.

11. Gardikis S, Antypas S, Mamoulakis C, Demetriades D, Dolatzas T, Tsalkidis A, et al. Colostomy type in anorectal malformations: 10years' experience. Minerva Pediatr. 2004 Aug;56(4):425-9

12. Elsayed RF, Kama] HA, El-Liethy NE. Recent advances in $\mathrm{MRI}$ in the preoperative assessment of anorectal malformations. The Egyptian Journal of Radiology and Nuclear Medicine. 2016;47(3):71 1-21 